Article

\title{
Negotiating Belonging as Cultural Proximity in the Process of Adapting Global Reality TV Formats
}

\author{
Laura Sūna \\ Institute for Media and Communication Studies, Freie Universität Berlin, 14195 Berlin, Germany; \\ E-Mail: laura.suna@fu-berlin.de
}

Submitted: 28 March 2018 | Accepted: 4 June 2018 | Published: 11 September 2018

\begin{abstract}
This article focuses on aspects of belonging the producers of reality TV programmes address in the staging of emotions. Based on interview statements by 12 experts from the field of national and international reality TV format production, we argue as follows: on the one hand, producers in reality TV shows address belonging as a perceived cultural proximity to trans-local meta-narratives of a longing for change, romantic love, competition and victory. The producers associate these trans-local meta-narratives with allegedly universal emotions. On the other hand, the producers address belonging as a perceived cultural proximity to local cultural discourses on beauty ideals and combine these with a specific local cultural performance of emotions. The results show that an emotional repertoire is developed and negotiated in the adaptation process of trans-local formats. It refers to universalistic understanding of emotional display and negotiates specific "feeling rules" accordingly.
\end{abstract}

\section{Keywords}

belonging; cultural proximity; emotion repertoires; emotions; feeling rules; format adaptation; reality TV

\section{Issue}

This article is part of the issue "The Turn to Affect and Emotion in Media Studies", edited by Margreth Lünenborg and Tanja Maier (Free University Berlin, Germany).

(C) 2018 by the author; licensee Cogitatio (Lisbon, Portugal). This article is licensed under a Creative Commons Attribution 4.0 International License (CC BY).

\section{Introduction}

The article's starting point is the assumption that emotions are extensively displayed in reality TV formats and that these emotions represent an essential moment of attraction for the audience. As Jelle Mast (2016) depicts fittingly, a key notion in reality TV is to take the audience on an emotional journey. Reality TV formats are primarily devised with the intent of creating stories and delivering entertainment by dramatic pleasures to the audience (Mast, 2016, p. 905). The format rules of globally traded TV formats encompass diverse narratives, rules of competition and audio-visual display techniques that provoke an affection and emotional response in the participants and audience. Developing an "emotional commitment" in the viewers-according to Henry Jenkins $(2009$, p. 348$)$-is one of the main goals of entertainment television. It provides viewer loyalty to the TV format and the products displayed there.
The study's subject is globally traded talent and dating shows. In order for globally traded entertainment formats to be successful in local territories, they are subject to specific cultural adaptations. In this context, we are interested in how allegedly global emotions are adapted to local cultural conditions in format production; i.e., how emotions are produced in the local adaptation of globally circulating reality TV formats. From a cultural studies perspective, we are particularly interested in the aspects of belonging and communitisation the producers of reality TV programmes address by presenting emotions. To what extent do reality TV formats provide proposals of proximity and distance by staging emotions? And how are feeling rules and emotional repertoires negotiated or redefined? Here we connect to the discussion on "affective citizenship" (Fortier, 2010, p. 19), as today the question of how one feels about the other group and its members has become relevant. Policy and media address "the 'affective subject'; that is, a subject whose conduct arises 
from desires, fears, anxieties, insecurities, affection, care, dis/trust, un/ease and so on" (Fortier, 2010, p. 19). All in all, the article asks how producers of reality TV formats address the affective citizen in their work.

\section{Belonging, Emotions and Cultural Proximity}

In order to maximise profits, global television formats try to reach as broad and heterogeneous an audience as possible and offer references for various viewers. Particularly, globally traded reality TV formats use universal topics that can be connected to different cultural contexts (Stehling, 2015, p. 60). In the TV shows, processes of inclusion and exclusion, as well as the creation (or refusal) of belonging are made visible by means of different, culturally diverse protagonists and implicitly connected emotional displays. A social distinction of ' $u$ ' and 'them' becomes visible; the formats relate to this and simultaneously provoke feelings of belonging in communities beyond the media and TV formats. The forms of communitisation can correspond with real social groups. At the same time, they can also address "imagined communities" (Anderson, 1991). The importance of media products for questions of belonging has so far been rather neglected in communication studies (Lähdesmäki et al., 2016, p. 242). The study presented here is dedicated to the analysis of forms of belonging in and by media products such as reality TV formats and focuses on their emotional and affective dimensions. These are understood with the concept of belonging in the sense of a feeling of affiliation (Lünenborg, Maier, Sūna, \& Töpper, 2018).

We define belonging as an "emotionally charged social location" (Pfaff-Czarnecka, 2012, p. 11) that is produced in relation to social groups, materialities, geographic spaces or media content. It is negotiated situationally and constituted by feelings of belonging (RöttgerRössler, 2016, p. 2). We assume that the location is based on affective practices. At the same time, such affective practices and emotions can also be the effect of this location. Individuals can have several affiliations to differently constituted collectives such as gender, ethnicity, nation or also association, family, school or peer group (Anthias, 2006, p. 26).

Furthermore, we explore to what extent producers of reality TV formats rely on an emotional and affective level in the performance and perception of commonality or difference as well as discursive attachments of communitizing meanings.

Emotions are understood here as social and cultural phenomena (von Scheve, 2017, p. 2). They are closely tied to knowledge systems, norms and values, which individuals do not always have to be aware of and are learned during socialisation (Hochschild, 1983). The expression and evaluation of emotions is therefore influenced by social and individual rules; Hochschild (1979) called them "feeling rules". Some of these rules can be (culturally) universal, while others apply only for a limited period or to certain social groups, within which they can also be used to distinguish the members from other collectives (Hochschild, 1979, p. 566). Culture, context and historicity therefore play a role for the specific emotional (expressive and behavioural) rules. Individuals have cultural knowledge about particular forms of expression and behaviour that provides orientation for which emotions are appropriate in which situations. An ensemble of such repetitive, socially rooted and regulated verbal and nonverbal emotional forms of expression and behaviour-on the basis of which emotions are ordered, evaluated and circulated-can be described as an emotional repertoire. Media products can be understood as a repository, carrier, mediator as well as context for producing and negotiating emotional repertoires. Social norms and values regarding the appropriateness of emotions are displayed and performed in audio-visual media. Media also contribute to the circulation of forms and patterns of emotional experience, behaviour and interaction. These rules can be confirmed, imitated, internalized or passed on, but also rejected or renegotiated by the media audience (Lünenborg et al., 2018).

As mentioned above, it is essential for the profitoriented production of a TV programme to achieve the highest possible audience rating and to bind as many loyal viewers to the programme as possible. Since these are trans-local reality TV formats, i.e., formats dispersed over diverse local contexts (Hepp, 2013) requiring local cultural adaptation, the actors involved in the production process aim to produce a connectivity to the format in the sense of a perceived local cultural proximity on the side of the audience. Such cultural proximity can lead to an identification with or a distinction from forms of belonging and communitisation addressed in the TV programme.

The term cultural proximity was introduced by Straubhaar (later developed further together with La Pastina), initially in the context of the trans-local reception of global media content. The term proximity also includes an allusion to belonging, a feeling of belonging to an imagined community (Straubhaar, 2007). Straubhaar addressed the question of why some international TV series are popular in various countries and others are not. Despite him analysing the TV audience, we see the potential to transfer these ideas to the TV production realm because the producers address an imagined audience and align their work with the anticipated preferences and belonging of this audience. La Pastina and Straubhaar summarise the core idea of the theory of cultural proximity as follows: "audiences will tend to choose to watch television programmes that are closest, most proximate or most directly relevant to them in cultural and linguistic terms" (La Pastina \& Straubhaar, 2005, p. 273).

Cultural proximity is created through historical spaces of common local culture and language, i.e., cultural references in the media text can be easily recognized and appropriated by the audience. The selection of media content can also be influenced by specific group affiliations (La Pastina \& Straubhaar, 2005). 
It is the local culture, meant as a familiar linguistic space of everyday culture, that shapes the intensity of the audience's perception of cultural proximity to a media text (La Pastina \& Straubhaar, 2005, p. 274). These are local cultural elements such as body language, emotional display, understanding humour, religious elements, etc. In addition, the concept of cultural proximity emphasises a plurality within the national/cultural context. Local culture is not equated with a national culture. In the context of globalisation and hybridisation of culture, viewers access and rely on various cultural contexts simultaneously that are not equal to a nation state. Thus, cultural proximity is also seen as plural. In fact, the audience of a TV programme consists of various sub-audiences. We assume that the producers of reality TV programmes consider these aspects in the adaptation process of the formats. They thus address individual parts of the audience to whom they ascribe specific local cultural interests.

Furthermore, La Pastina and Straubhaar (2005, p. 274) emphasise that cultural proximity can also emerge independently of its local cultural references. They argue that cultural proximity to a media content can emerge on a transnational level as genre proximity, as value proximity and thematic proximity (La Pastina \& Straubhaar, 2005, p. 286). In contrast to La Pastina and Straubhaar, we prefer to use the term trans-local instead of transnational. According to Hepp (2013, p. 70), the term "trans-locality" describes cultural spaces beyond national frameworks and cultural phenomena that circulate beyond local cultural contexts. The familiarity with the narrative styles and display techniques of a TV genre such as reality TV is present in various cultural contexts and thus enables trans-local cultural proximity to a TV product. These are cultural references that are compatible trans-locally; for example, certain universal values, images, archetypes, themes and narrative structures (Grüne, 2016, p. 144). Overall, it should be emphasised that the attractiveness of a trans-local TV programme for viewers lies in a combination of trans-local and local references that they find comprehensible. This means that, for example, the universal images are adapted to the familiar linguistic space of everyday culture.

In their work, producers of reality TV formats draw on the specific (anticipated) expectations of the audience that can be described as the idea of cultural proximity. Having said that, we will analyse the specific discursive references in reality TV that offer a feeling of cultural proximity on both a local cultural and a trans-local level. This proximity can then result in forms of belonging for the anticipated audience. We are particularly interested in emotions addressed in the production of these discursive references.

The production of trans-local television formats is shaped by various actors. Among them are the TV networks, who as programme providers decide on the formats to be procured, produced and broadcasted. However, the production companies are responsible for im- plementing a program and adapting the trans-locally traded format to local conditions (Grüne, 2016, p. 77). As a rule, the licensor is represented by consultants called 'flying producers' who accompany and control the adaptation process in accordance with the format license (Altmeppen, Lantzsch, \& Will, 2007, p. 101). The producers of entertainment formats must be considered as gatekeepers, since they decide which trans-local formats are to be adapted for the local market and also influence the specific local reinterpretation of the original format. Producers use the contractually agreed creative freedom of the format to make it effective and comprehensible in the specific reference area. Grüne (2016, p. 381) describes format adaptation as a hybridisation of strategic, intentional and organisational practices of the actors involved in production; these shape cultural recombination and possible selection of local and trans-local interpretative patterns. Based on such observations, we examine which local and trans-local frames of references producers rely on in their everyday working process of format adaptation.

After a short description of the method, these two levels of production and negotiation of belonging by cultural proximity will be presented along with statements by national and international producers of reality TV. In the following sections we argue as follows: on the one hand, the producers address belonging as a perceived cultural proximity to trans-local meta-narratives in the reality TV programmes. They associate these metanarratives with allegedly global emotions and emotional repertoires. On the other hand, the producers approach belonging as a perceived cultural proximity to local cultural aspects and relate these with a specific local cultural performance of emotions.

\section{Method and Data}

Since the production of reality TV shows is a relatively closed area, we rely on statements by people involved in the programmes' production. The best way to gain such knowledge is to perform expert interviews as a method.

According to Blöbaum, Nölleke and Scheu (2016), expert interviews can be defined as guided interviews with role bearers of different social/cultural areas. One of the advantages of expert interviews is that the experts generally have a high level of linguistic and social competence; this allows statements to be made on complex or prelinguistically and unconsciously defined topics such as affects and emotions (Blöbaum et al., 2016, p. 176). We are interested in the explicit knowledge of e.g., production processes and implicit (because often hardly reflected) knowledge about "emotion rules" and emotion concepts. If we focus on the area of emotions from the perspective of experts, it must be noted that they are both involved in shaping the emotional process of programmes and are emotionally involved in the programmes themselves (Kleres, 2015, p. 91). Wolfgang Dunkel and Margit Weihrich (2013, pp. 107-108) distinguish between three 
dimensions of emotional labour. Emotions as an object of work, emotions as a means of work and emotions as a condition for the work (work on one's own feelings, for example in the form of feeling rules or professional standards). In the context of our study, this means that the producers work-on the one hand-on emotions and with the emotions of others, and-on the other handthey must regulate their own emotions. The producers aim to tell the audience an emotional story (emotions as the subject of the work) by using format rules and staging strategies (emotions as a working tool), which should evoke a certain emotional performance of the participants and an emotional and affective attachment of the audience to the programme. At the same time, the producers themselves are emotionally involved in the work (working on their own feelings); for example, if the professional feeling rules do not correspond to the individual rules or the individual feelings take over in the professional context. In the following sections, we will focus on the part of the study that relates to emotions as the subject of the work and as a working tool. These are emotions that should contribute to the financial success of the TV format from the point of view of the producer. These are emotions performed by the contestants and anticipated emotions of the format audience (for an analysis on emotion labour of the producers see Lünenborg et al., 2018).

The experts for the study were recruited with a snowball method, i.e., the experts already interviewed recommended further possible interview partners. All in all, it was important to meet a possible variance of functions and reality TV formats that were of interest to us. In the sense of "theoretical sampling" (Strauss \& Corbin, 1990), we interviewed various people involved in the production process: this included employees of local production companies that produce talent and dating formats such as Germany's Next Topmodel, The Bachelor, The Voice and Pop Idol. At the same time, we were interested in people who develop, accompany and produce globally traded formats, so-called "flying producers" (Altmeppen et al., 2007, p. 101). We interviewed directors, executive producers, casting agents, people responsible for the development and sales of formats, as well as directors of the editorial offices, who introduce the reality TV shows to TV networks. A theoretical saturation was achieved with a total of 12 experts (see Table 1). The interviews were conducted between January and March 2016 in German and English and had an average length of about 40 minutes.

The transcripts of the interviews were analysed by a coding process oriented to qualitative content analysis (Mayring, 2008). After an open coding, sensitizing concepts (Strauss \& Corbin, 1990) were developed and used for a repeated coding with the software MaxQDA. Five main categories were developed, each (with the exception of one) had several sub-categories. The main categories were: trans-local cultural references; local cultural references; belonging; emotion work; and professionality. The first three main categories were used to explain the overall category of cultural proximity. The category of belonging described passages in the interview material concerning notions of inclusion and exclusion, feelings of affiliation and positioning in relation to social groups and ascriptions in the context of gender, ethnicity, nation, class and others. Trans-local cultural references and local cultural references were described through the statements about the spatiality of cultural meanings. Cultural proximity was then located in the context of emotional and affective positioning to different cultural products, references and discourses. For example, signifiers such as "my/their culture", "our media stars", "comprehensible for us" describe the perceived cultural relevance and closeness to a media text. In the following sections, a part of the analysis from this coding process will be displayed.

\section{Production and Negotiation of Perceived Belonging as Cultural Proximity}

\subsection{Belonging as Cultural Proximity by Trans-Local Cultural References}

Since they circulate trans-locally, reality TV formats are based on certain aspects that are trans-locally compatible for viewers. These are integrated in the format structure and rules (Lantzsch, 2008, p. 165). Using empirical material from the expert interviews, we want to show which trans-local themes understood as meta-narratives have, from the point of view of the producers, the potential to create a feeling of proximity in the audience to a reality TV format. The term "narrative" describes an established story that transports values and emotions, is related to a certain cultural context and is subject to change over time (see Seibel, 2009). With the prefix 'meta', we underline the widespread-i.e., trans-local validity-of the narrative.

Reality TV formats are designed to provide an intense emotional experience to the viewers. Several interviewed experts state that this is the programmes' goal and thus also one of the most important themes of audience loyalty to the format and TV show, as it guarantees an "emotional commitment" (Jenkins, 2009) on the side of the audience. The producers use terms such as "strong emotional moment" (12) or the "emotional impact" (01) of a scene in the programme and thus estimate the potential for affection for the programme's audience. ${ }^{1}$ This confirms the producers' position among the various players in the format market as described above. The producers are strongly interested in the financial success of their TV program. Among other things, this is their guiding motive during the production or adaptation of translocal formats.

The producers try to tell "emotional stories" (01) in their programmes so that the viewer can experience an "emotional journey" (Mast, 2016). Typical for reality TV

\footnotetext{
${ }^{1}$ The numbers in brackets refer to the experts listed in Table 1.
} 
Table 1. List of the interviewees.

\begin{tabular}{|c|c|c|c|c|}
\hline & Name & Institution & Position & Format \\
\hline 1 & Brauer, Daniel & $\begin{array}{l}\text { Masterfilms: Film- und } \\
\text { Fernsehproduktion GmbH } \\
\text { and Talpa Germany }\end{array}$ & $\begin{array}{l}\text { Producer, Head of Reality, } \\
\text { i.e., Field Director \& } \\
\text { Creative Director }\end{array}$ & $\begin{array}{l}\text { The Voice of Germany, } \\
\text { Germany's Next Topmodel }\end{array}$ \\
\hline 2 & Fraser, Shona & RTL II & $\begin{array}{l}\text { Director Entertainment \& } \\
\text { Development }\end{array}$ & $\begin{array}{l}\text { Germany's Next Topmodel, } \\
\text { Popstars, Deutschland } \\
\text { sucht den Superstar/ } \\
\text { Pop Idol, Survivor }\end{array}$ \\
\hline 3 & Fuchs, Oliver & $\begin{array}{l}\text { Bavaria Entertainment } \\
\text { GmbH }\end{array}$ & Managing Director & $\begin{array}{l}\text { The Bachelor, German } \\
\text { Formats }\end{array}$ \\
\hline 4 & James, Dug & FremantleMedia (UK) & $\begin{array}{l}\text { Vice President of Global } \\
\text { Development }\end{array}$ & American Idol \\
\hline 5 & Jamm, René & $\begin{array}{l}\text { Warner Bros. International } \\
\text { Television Production } \\
\text { Germany GmbH }\end{array}$ & CEO & $\begin{array}{l}\text { The Bachelor, } \\
\text { The Bachelorette }\end{array}$ \\
\hline 6 & Ketelaar, Taco & $\begin{array}{l}\text { Freelance, previously Sat.1 } \\
\text { (Germany); } \\
\text { Endemol International } \\
\text { (The Netherlands) }\end{array}$ & $\begin{array}{l}\text { Senior Vice President } \\
\text { Prime Time Entertainment } \\
\text { \& Reality }\end{array}$ & $\begin{array}{l}\text { The Voice, The Voice Kids. } \\
\text { Utopia, Fear Factor, } \\
\text { Who Wants to Be } \\
\text { a Millionaire? }\end{array}$ \\
\hline 7 & Küttner, Markus & RTL & $\begin{array}{l}\text { Director Comedy \& Real } \\
\text { Life }\end{array}$ & $\begin{array}{l}\text { The Bachelor/ } \\
\text { The Bachelorette }\end{array}$ \\
\hline 8 & Mival, Jennifer & $\begin{array}{l}\text { Seapoint Productions } \mathrm{GmbH} \\
\text { \& Co. }\end{array}$ & $\begin{array}{l}\text { Head of Formats \& } \\
\text { Creative Partnerships }\end{array}$ & Pop Idol, The Bachelor \\
\hline 9 & Rademacher, Asita & $\begin{array}{l}\text { Warner Bros. International } \\
\text { Television Production } \\
\text { Germany GmbH }\end{array}$ & Head of Casting & $\begin{array}{l}\text { The Bachelor/ } \\
\text { The Bachelorette }\end{array}$ \\
\hline 10 & Rentmeister, Käthe & $\begin{array}{l}\text { Warner Bros. International } \\
\text { Television Production } \\
\text { Germany GmbH }\end{array}$ & $\begin{array}{l}\text { Head of Development \& } \\
\text { Sales }\end{array}$ & $\begin{array}{l}\text { The Bachelor, } \\
\text { The Bachelorette }\end{array}$ \\
\hline 11 & Winnan, Dave & ITV Studios (UK) & $\begin{array}{l}\text { Director of International } \\
\text { Production and Development, } \\
\text { In-House 'Flying Producer' }\end{array}$ & $\begin{array}{l}\text { Dancing on Ice: Finland. } \\
\text { I'm a Celebrity, Get Me } \\
\text { Out of Here }\end{array}$ \\
\hline 12 & Wood, Gavin & $\begin{array}{l}\text { The Producers Ltd. } \\
\text { (New Zeeland) }\end{array}$ & Producer & $\begin{array}{l}\text { Indian Idol, } \\
\text { New Zealand Idol }\end{array}$ \\
\hline
\end{tabular}

formats are emotions like joy, hate and schadenfreude. Producers interviewed by us argue that strong emotions performed by protagonists usually lead to a strong emotional attachment by the viewers to the programme. An internationally acting producer describes his opinion about the audience of reality TV shows as follows (12):

People like to sit up and make decisions. I like you; I don't like you...you know. I better like her. I like him; I want him to win. I always say to people overseas that you know you've done well if you can force a love-hate relationship between the contestants and the viewer. And it is really that strong. Emotionally, the strength of the relationship is what gets you. You want them to say: 'Oh, I love that guy. He's fantastic, I want him to win'. And they watch and they watch....So the trick is always to engage the viewer at home on an emotional level. Keep him entertained, but also: keep him talking. (12)

From the point of view of the producers, the diverse emotional experience in and during the programme is what makes the programmes so appealing to viewers. With this emotional experience, group dynamics are activated-feelings of belonging and efforts of separation can arise. The people involved in the production make every effort to enable the most intense emotional experience possible with the help of various production techniques. This is achieved, as can be seen in the quote, by a polarized representation of allegedly 'universal' emotions such as love and hate. The producers point out that the negotiation of emotions and a perceived 
positioning to the represented communities by the audience is social-relational, because they are negotiated during or after the reception of the TV show.

At this point the reliance of the producers on the cultural proximity of the audience on the level of the genre becomes visible. They regard the possibility of having an intense emotional experience, which is realised via proposals of identification with and separation from the protagonists, as is characteristic for the trans-local circulating genre of reality TV. The producers follow an essentialist wold view and argue that the genre of reality TV provides entertainment by dramatic pleasures as it connects positive and negative emotions in one format.

The anticipated emotional experience of the programmes is guaranteed by the meta-narratives built into the formats. Overall, during the production of various reality TV formats, the producers refer to three trans-local meta-narratives, which are associated with specific emotions and could ensure cultural proximity of the audience as thematic proximity. These are: a) longing for a "lifechanging-moment" that is connected with excitement and compassion; $b$ ) the narrative of a fairy-tale romance associated with the longing for true love; c) a longing for competition and victory, which is connected to neoliberal values of success and working on oneself and can activate emotions such as compassion, indulgence of success, envy and schadenfreude. These three points will be explained in more detail below.

One of the central narratives upon which, according to the producers' statements, most reality TV formats are based, is the longing for a life-changing-moment. The programmes' participants enter TV reality and can change their lives by exhibiting their bodies in public, seeking love and partnership, winning a sum of money or changing their lives in some other way. The producers connect this particular meta-narrative to the arousal of a feeling of involvement, empathy, compassion and voyeurism on the side of the audience. The participants of the programmes undergo a change that makes the programme exciting and, in turn, comprehensible:

The transformation in reality TV is so good because it changes the person's perception of themselves. A swap from the ugly duckling into the swan. (12)

This metaphor, chosen from the realm of fairy tales, refers to the promise of leaving the rules and conventions of everyday life and crossing borders. In the eyes of the producers, the audience is given the chance to participate without risk in a border-crossing experience. The emotional promise of reality TV is thus aimed at breaking with everyday conventions-a promise of adventure, daring and change. Since the spectators remain safe in their domestic life, it is an issue of participating in an emotional journey. The formats' candidates represent this change in place of the spectators.

This trans-local narrative of change should encourage the audience to position themselves in relation to the programme's protagonists and events. Producers connect this to the idea of a sense of belonging and thus see it as bonding to the format:

I guess empathy is the big one, because you want to see your hero succeed and your villains fail. And you want to see slightly bad people become good and develop in that way. It's very basic storytelling. It's not complex; it's been going on for thousands of years. These are the kinds of stories that we're telling. (04)

The staging of the programme's story refers to the archaic dual structure of good and evil, which the producers have been regarding as trans-local, 'universal' and valid in the societal storytelling for years. This in turn offers the viewer a simple perceived positioning to the depicted affiliations-an 'us'-and-'them' positioning.

As a second trans-local meta-narrative, longing for fairy-tale-like romance is addressed, which the producers depict as a "Cinderella story" (07), "The story with the prince" (05) or as "fairy-tale-like reality dating story" (07). The experts associate this theme of fairy tales with American/Western popular culture. For example, participants in the programme The Bachelor are compared to the American cult dolls Barbie and Ken. The programmes are therefore purposefully produced "a little over the top" (07), in order to provide a clear reference to popular culture for the audience.

It's a dream world; these are beautiful places we're going to. They're great locations, they're great dates to go. And you want to see great people and experience great kisses and great roses....It's all beautiful. (09)

The atmosphere of the programme is supposed to trigger an idea of a dream-like love story on the part of the participants and viewers. The idea of a trans-local male and female ideal of beauty is stylized as overstated glamour, allegedly characteristic for American popular culture and displayed as something that feels beautiful. It also should create an atmosphere of a world that is special and almost unattainable.

The third trans-local meta-narrative upon which producers rely in the production process is longing for competition and victory. Most reality TV formats are based on the idea of a competition incorporated into the format rules. For example, in dating shows the participants compete for the sympathy of the male contestant. Talent shows such as Germany's Next Topmodel have the character of a beauty contest; the participants battle for the title of the best top model. Due to the competition situation that is inscribed in the format, the protagonists are intensely emotionalised. The producers hope that this in turn can evoke distancing or approving involvement on the part of the spectators.

The competition is also associated with a longing for recognition by reference persons. From the producers' point of view, the audience is fascinated by the excite- 
ment for the achievement of the favourites on the one hand and, on the other hand, by connecting with the depicted competitive situation.

The official confirmation from a jury member. Well, that's competition. How do I behave in a competitive situation? Comparing: am I better than you? Actually, it is the need to say to the assembled team and to the assembled country: I am better than others. They are very universal mechanisms. (08)

In the trans-local narrative of the competition, which underlies most reality TV formats, producers associate with emotions of compassion, the indulgence of success, schadenfreude and envy. From the producers' point of view, these emotions ensure a strong emotional connection to the programme and identification or distinction of the viewers towards various social groups. The producers describe the need for comparison and positioning within social groups as a universal narrative that functions similarly for reality TV formats in various countries. Especially schadenfreude and the voyeuristic joy of watching protagonists miss their goals is easily activated in the audience through this narrative, the experts state in interviews.

The best reality television is when you shatter someone's dream who believes that they're going to win....Some of the breakdowns we've had, emotional breakdowns or anger at being kicked out, are quite amazing. In their hearts, they believed that they were going to win. And watching that meltdown, watching them break down, watching that shattering of their dream is the reality goal the viewers hang on for. It certainly is the best to watch. And they will share their emotions. When I see people sitting at home crying about someone being knocked out onscreen that night, then I know I can say that that's good reality TV. Because you actually draw on the viewer. They become part of the programme and you get them engaged. (12)

Viewers' potential empathetic involvement with destinies on a show and the indulgence of success is also seen as important for a show's financial success. The quote aptly describes the strong orientation towards the emotional involvement of the audience.

However, to ensure that the global format functions well and that viewer interest remains equally high, the rather negatively connoted emotions such as schadenfreude or envy, to which the producers allude to in the programmes, are simultaneously linked to a positive prevailing mood. From the point of view of the producers, the viewer is interested in an overall positive television reception experience. His or her negative emotions, caused by the social detachment of joy given the failure of others' dreams, need to be balanced by a positive overall mood. Producers state that this allows the viewer to have fun while watching someone's dreams shatter and to not feel guilty in the process.

In the next step, we want to look at the extent to which producers address local cultural aspects in their production work.

\subsection{Belonging as Cultural Proximity by Local Cultural References}

The extent to which a format must and can be adapted to local conditions is largely determined by the format owner and the format rules. How exactly the adaptation is realised, however, as described earlier, depends mainly on the local production team and the television network that will broadcast the programme. Local producers are mainly responsible for local accessibility for a trans-locally circulating TV format (see Esser, 2010, p. 289). As elaborated, we speak of local cultural references rather than national cultural aspects. This takes account of the fact that cultural spaces do not always coincide with nation-state spaces.

The interview material shows producers' efforts to establish local cultural close coding during production, i.e., the producers integrate various local, regional and national representations into existing trans-local show concepts, which in turn potentially evoke feelings of proximity on the part of the viewers. The necessity of a local cultural adaptation of a trans-local format justifies a 'flying producer' as follows: the TV audience has a need to watch TV programmes produced for their cultural space. The viewer therefore prefers stories and protagonists with local cultural connotations that feel culturally comprehensible and close to him or her. Several producers state: a trans-local format must be able to relate in an affective and emotional way to the viewer's local environment. They are convinced: local culture is located in the affective corporal performance of the participants, programme jury and live audience, which the producers call "the locals": "What they bring with them feels very local" (08).

The locally connected, atmospheric "look and feel" of a programme thus creates local cultural proximity in the audience, several experts state. The audience should thus feel the locality or perceive the programme as locally appealing. If this feeling of local cultural proximity is established in the audience to the format, a format adaptation can be successful.

A decisive aspect in the adaptation of trans-local TV formats is, according to producers' statements, the positioning of the format in local cultural discourses. Discourses here are seen in a simplified way and based on Foucault (1972) as the understanding of reality in a cultural context, in the framework of which rules of the appropriateness of, for example, language expression or emotional display are defined. Discourses producers rely on strongly intertwine with local popular culture and are reproduced by the media industry. Producers are convinced that if this discursive positioning is successful during adaptation, then there is a high probability that the 
programme will activate a feeling of belonging to the local cultural space among the audience and thus also strengthen an identification with the format. Producers connect it to a confirmation of the feeling of a local cultural home: For the audience it should feel familiar and understandable.

Since the formats of talent and dating shows we analyse are strongly oriented towards the physical and aesthetic level, one of the most important discourses to which the producers refer is the local, culturally typical ideal of beauty. They take the beauty discourses promoted in local cultural entertainment industries and apply them, for example, to the selection of programme protagonists.

We look which German type of man is popular now. And he's kind of a muscle guy, who has a nice face, who lisps and squints a little. The last one [bachelor] was rather blonde, and then there was the time when soft guys were popular....You are casting. For The Bachelor, the magazine $\mathrm{GQ}$ is relevant; you can see the guys who are popular there. The type of men who are now popular in movies. M'Barek is this muscle guy, a macho type. (05)

The mediatised discourses of beauty are thus further confirmed in reality TV programmes. The same applies to the programmes' hosts and jury; they are local media and show celebrities. Thus, "local" refers to a mediatised cultural proximity that is established within a mediatised reference system.

In addition, the local celebrities are associated with a specific emotional performance that is determined by the media discourse about them. Such local celebrities as Heidi Klum, Dieter Bohlen or Simon Cowell, who act as jurors or moderators of reality TV shows, are presented as expressive and exciting for the audience. At the same time, the cultural industry refers to programme protagonists who have a high affection potential. The media cross-referentiality turns them into new media stars. This in turn increases the visibility and popularity of the format. As a circuit of attention, it can be seen as a part of an "affective economy" (Ahmed, 2004). In addition, various local media products such as women's magazines or movies are seen by the producers as a representation of viewer preferences and their sense of beauty.

The producers locate the local feeling' of a programme in the participants' affective/corporal performance. Purposeful casting estimates a certain potential of performativity of a person's emotions. This assessment is based on local cultural concepts that we classify as "culturalistic". Similarly, they connect what is seen as an appropriate emotional reaction-in the sense of 'feeling rules' and conventions of emotional display-with local cultural differences.

When I watch it, it feels to me like the reactions are not big enough and you know there is not enough emotion there. But I'm not the viewer in Sweden; I don't have to feel that it works for me. But for Swedish viewers, they enjoy the satiety and they enjoy the fact that the emotion for them is kind of hidden under the surface-you can watch that emotion bubbling up rather than having a situation in which as soon as someone gets angry they shout and have a big argument in the middle of the house. That wouldn't be real, and it wouldn't work, because it's not typical for Swedes. (04)

At the same time, producers assume that the participants will align their emotional and affective performance with local and trans-local popular cultural discourses about the programme. This is connected to the situational reproduction and simulation of emotional repertoires, causing partly conscious regulation and pretending.

The producers associate the temporality or intensity of the participants' emotional display with local cultural characteristics, which can also be described as culturalistic. For example, a 'flying producer' calls it the "equatorial shift" (11) and thus describes the differences in emotional display using a north-south axis as an explanation. According to this idea, the Nordic countries are "less sentimental countries" (11) and more reserved in their emotional expression, whereas the southern countries are strongly expressive. It becomes clear that reality TV formats in which producers refer to such culturalistic concepts actually reproduce them. Reality TV itself generates the rules according to which Swedes must be considered reserved and Germans as slow. Here, the performative production of (national or cultural) feeling rules in and by reality TV becomes visible.

All in all, the local adaptation of trans-local TV formats is based on mediatised popular cultural discourses and thus attempts to evoke a local cultural proximity on the part of the audience via local participants' emotional performance. It becomes clear that the contexts considered by producers as locally cultural are mediatised and shaped by western popular culture. Allegedly local narratives have a connotation of a global economy of prosperity and success; through the mediatisation of everyday life (Hepp, 2013), they have found their way into the local cultural perception of the audience or, from the perspective of the producers, should have found their way there.

This description of these two levels-local and translocal-has an analytical purpose, which should show how the producers build on their stereotypical notion of local and trans-local cultural proximity of the audience while adapting a format. During production, they try to establish strong audience links, both at the level of local and trans-local cultural proximity.

\section{Conclusion}

Our starting point was the question of the extent to which producers of trans-local reality TV formats ad- 
dress viewers' perceived proximity to various communities. The study has shown that in reality TV, displayed emotions can provide the proposals for social location of viewers. The expert interviews revealed producers' efforts at addressing proximity on the part of the audience at a trans-local level of meta-narratives and at a local cultural level of discourses, which in turn were associated with a specific emotional performance. Paradoxically, it becomes clear that these emotions displayed in reality TV formats, which are associated with trans-local metanarratives and local cultural discourses, address similar affiliations and communitisation. These, for example, include: an imagined community of success in the context of a neo-liberal competition; communitisation by means of a middle-class and media-critical discourse, which becomes visible in the form of a perceived cultural distance and distinction from various social groups; belonging to the imagined taste community of local and trans-local popular culture; belonging to an imagined community of values, which is negotiated by specific emotional expressions and "feeling rules". The efforts of the producers to address trans-local and local references in the production of reality TV programmes thus activate a complex structure of emotionally charged social location that display a relation to different social groups.

As we stated earlier, we assume that reality TV formats as popular cultural media products have a considerable role in the regulation, conventionalisation and commodification of emotions. Here we argue that reality TV formats act as emotional repertoire (see Slaby, Mühlhoff, $\&$ Wüschner, 2016, p. 82). The power of an emotional repertoire is produced, confirmed and/or challenged in the sense of continuous processes of inclusion and exclusion, especially in the narration of popular media texts. Hickethier (2007) describes television as the industrialisation of emotions. He assumes that, over a certain period of time, expected, genre-constituting emotional repertoires for TV formats are performed in specific scenarios and subjected to a market logic applicable to the TV format. The emotions performed by the candidates become a calculable commodity, which is evaluated and, if necessary, sanctioned or positively emphasised (Lünenborg et al., 2018). Such a commodification of emotions, i.e., the unconditional availability of emotional expressions with a view to their economic viability, fundamentally characterises formats of reality TV. The emotional repertoire of reality TV programmes has to be seen as part of an affective economy (Ahmed, 2004): emotions and associated affective location as perceived cultural proximity or distance are understood, staged and circulated as economically viable. Our study shows that in their work during format adaptation and production, the producers have universalistic and culturalistic ideas about the applicable emotion display and feeling rules, which are bound to a market logic or commodification. They strongly influence the feeling rules and emotional displays that are legitimate in the context of affective economies. Producers hope that the audience confirms, imitates and internalises these rules. But they can also reject and renegotiate them in terms of ironic and critical reception. In any case, these emotional repertoires have a socio-political influence and shape the opinion of the "affective citizen". Here we rely on the perceived cultural proximity and distance that is negotiated in reality TV formats.

\section{Acknowledgments}

I wish to thank Margreth Lünenborg, Claudia Töpper and Marten Brehmer for the helpful support in the writing process of this article. I would also like to thank the anonymous reviewers for important comments and suggestions for the improvement of the paper. The research was funded by the German Research Foundation and is part of the collaborative research centre "Affective Societies" at the Freie Universität Berlin, Germany. Open Access Funding provided by the Freie Universität Berlin.

\section{Conflict of Interests}

The author declares no conflict of interests.

\section{References}

Ahmed, S. (2004). Affective economies. Social Text, 22(2), 117-139.

Altmeppen, K.-D., Lantzsch, K., \& Will, A. (2007). Flowing networks in the entertainment business: Organizing international Tv format trade. International Journal on Media Management, 9(3), 94-104.

Anderson, B. (1991). Imagined communities. Reflections on the origin and spread of nationalism. New York, NY: Verso.

Anthias, F. (2006). Belongings in a globalising and unequal world. Rethinking translocations. In N. YuvalDavis, K. Kannabiran, \& U. M. Vieten (Eds.), The situated politics of belonging (pp. 17-31). London: SAGE Publications Ltd.

Blöbaum, B., Nölleke, D., \& Scheu, A. (2016). Das Experteninterview in der Kommunikationswissenschaft. In S. Averbeck-Lietz \& M. Meyen (Eds.), Handbuch nichtstandardisierter Methoden in der Kommunikationswissenschaft (pp. 175-190). Wiesbaden: Springer VS.

Dunkel, W., \& Weihrich, M. (2013). From emotional labor to interactive service work. In G. Koch \& S. Everke Buchanan (Eds.), Pathways to empathy (pp. 105-122). Frankfurt am Main: Campus.

Esser, A. (2010). Television formats: Primetime staple, global market. Popular Communication, 8(4), 273-292.

Fortier, A.-M. (2010). Proximity by design? Affective citizenship and the management of unease. Citizenship Studies, 14(1), 17-30.

Foucault, M. (1972). The archaeology of knowledge and the discourse on language. New York, NY: Pantheon Books. 
Grüne, A. (2016). Formatierte Weltkultur?Zur Theorie und Praxis globalen Unterhaltungsfernsehens. Bielefeld: transcript.

Hepp, A. (2013). Medienkultur. Die Kultur mediatisierter Welten. Wiesbaden: VS Verlag für Sozialwissenschaften.

Hickethier, K. (2007). Die kulturelle Bedeutung medialer Emotionserzeugung. In A. Bartsch, J. Eder, \& K. Fahlenbrach (Eds.), Audiovisuelle Emotionen. Emotionsdarstellung und Emotionsvermittlung durch audiovisuelle Medienangebote (pp. 104-122). Köln: von Halem.

Hochschild, A. R. (1979). Emotion work, feeling rules, and social structure. American Journal of Sociology, 85(3), 551-575.

Hochschild, A. R. (1983). Managed heart: Commercialization of human feeling. Berkeley, CA: University of California Press.

Jenkins, H. (2009). Buying into American idol. How we are being sold on reality television. In S. Murray \& L. Ouelette (Eds.), Reality TV. Remaking television culture (pp. 343-362). New York, NY: New York University Press.

Kleres, J. (2015). Emotional expertise. Emotions and the expert interview. In J. Kleres \& H. Flam (Eds.), Methods of exploring emotions (pp. 90-100). New York, NY: Routledge.

La Pastina, A. C., \& Straubhaar, J. D. (2005). Multiple proximities between television genres and audiences: The schism between telenovelas' global distribution and local consumption. The International Journal for Communication Studies, 67(3), 271-288.

Lähdesmäki, T., Saresma, T., Hiltunen, K., Jäntti, S., Sääskilahti, N., Vallius, A., \& Ahvenjärvi, K. (2016). Fluidity and flexibility of "belonging": Uses of the concept in contemporary research. Acta Sociologica, 59(3), 233-247.

Lantzsch, K. (2008). Der internationale Fernsehformathandel: Akteure, Strategien, Strukturen,
Organisationsformen. Wiesbaden: VS Verl. für Sozialwissenschaften.

Lünenborg, M., Maier, T., Sūna, L., \& Töpper, C. (2018). Ordnung durch Affekte: Emotionen, Belonging und Citizenship in Reality TV. Manuscript in preparation.

Mast, J. (2016). Negotiating the 'real' in 'reality shows': Production side discourses between deconstruction and reconstruction. Media, Culture \& Society, 38(6), 901-917.

Mayring, P. (2008). Die Praxis der qualitativen Inhaltsanalyse. Weinheim: Beltz.

Pfaff-Czarnecka, J. (2012). Zugehörigkeit in der mobilen Welt. Politiken der Verortung. Göttingen: Wallenstein.

Röttger-Rössler, B. (2016). Multiple Zugehörigkeiten. Eine emotionstheoretische Perspektive auf Migration (Working Paper SFB 1171). Berlin: Collaborative Research Centre Affective Societies at Freie Universität Berlin.

Seibel, W. (2009). Hegemoniale Semantiken und radikale Gegennarrative. Center of Excellence Cultural Foundations of Social Integration. Retrieved from www.exzellenzcluster.uni-konstanz.de

Slaby, J., Mühlhoff, R., \& Wüschner, P. (2016). Affektive Relationalität. Umrisse eines philosophischen Forschungsprogramms. In U. Eberlein (ed.), Zwischenleiblichkeit - Intercorporeity, Movement and Tacit Knowledge. (S. 69-108). Bielefeld: transcript Verlag.

Stehling, M. (2015). Die Aneignung von Fernsehformaten im transkulturellen Vergleich. Wiesbaden: Springer Fachmedien Wiesbaden.

Straubhaar, J. (2007). World television: From global to local. Newcastle upon Tyne: SAGE.

Strauss, A. L., \& Corbin, J. M. (1990). Basics of qualitative research: Grounded theory procedures and techniques. Newcastle upon Tyne: SAGE.

von Scheve, C. (2017). A social relational account of affect. European Journal of Social Theory, 21(1), 39-59.

\section{About the Author}

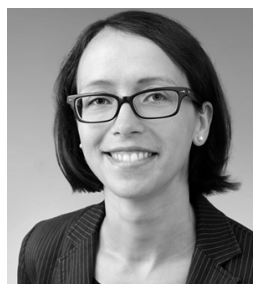

Laura Sūna (PhD) is Postdoctoral Researcher at Freie Universität Berlin, Germany. She is currently working in a research project on "Transcultural Emotional Repertoires in and by Reality TV" at the Collaborative Research Centre Affective Societies. Previously, she was a part time Lecturer at the Institute for Media and Communication Studies at Freie Universität Berlin and a Scientific Assistant at the University of Bremen, Germany and the University of Latvia, Latvia. Her research interests focus on emotions, reality TV, youth cultures, migration studies, cultural studies and qualitative research methods. 